\title{
Impregnação da \\ Superfície de Filmes \\ Poliméricos com Sulfeto de Cobre
}

\author{
Fernando A. da Silva, Eliete F. M. Madeira \& Katienne A. Linhares
}

O estudo dos polímeros é uma das principais áreas de estudo de novos materiais, e como exemplo de novos polímeros temos, os polímeros condutores. Na busca de materiais poliméricos com características condutoras uma das opções é mesclar as propriedades dos polímeros com características de materiais completamente diferentes como os metais. Com isso, o presente trabalho apresenta a síntese de compósitos polímero/sulfeto de cobre. Através da análise das bandas de absorção dos compósitos obtidos, observadas no infravermelho, evidencia-se a modificação da superfície do PEAD e PEBD pela oxidação, sendo assim, possível à impregnação do íon metálico, portanto, para os valores encontrados nos testes dos compósitos de polímeros com o cobre podemos perceber um considerável aumento na condutividade.

Palavras-chave: compósito, polímero, cobre.

The study of polymers is one of the principal areas of study of new materials, and as example of new polymers there are polymer drivers. In the search of materials polymeric with characteristic drivers one of the options is to mix the properties of the polymers with characteristics of completely different materials like the metal. The present work presents the synthesis of composites polymer/sulfide of copper. Through the analysis of directions of absorption of the obtained composites, observed in the infrared one, there shows up the modification of the surface of the PEAD and PEBD for the oxidation, which possibly to the impregnation of the metal ion. The values found in the assays of the composites of polymers with the copper we can realize a considerable increase in the conductivity.

Keywords: composites, polymer, copper. 


\section{Introdução}

Materiais antes utilizados em nosso dia-a-dia nem sempre conseguem suprir todas as funções que lhes são propostas quando em contato com novos equipamentos mais tecnológicos em novas situações. A busca por materiais que possam atender a diversas funções práticas e chegue o mais próximo possível da idealidade é grande, e pesquisas sobre materiais com melhores características e que possam vir a substituir materiais anteriores e com uma melhor eficiência são cada vez mais comum. Os alvos dessas pesquisas são a produção de materiais que possam ser, por exemplo, biodegradáveis, isolantes térmicos, isolantes acústicos ou condutores elétricos em potenciall.

Uma das principais áreas de novos materiais é a área dos polímeros ${ }^{2}$. Como exemplo de novos polímeros temos os polímeros condutores, e para se obter esses materiais, pesquisadores não se restringiram apenas a mudanças nas estruturas desses polímeros, mas também à procura de uma mistura de materiais ${ }^{3}$. Assim tem sido possível mesclar as propriedades dos polímeros com características de materiais completamente diferentes como os metais.

Este presente trabalho tem como objetivo a síntese de compósitos polímero/sulfeto de cobre que tenham baixa resistência elétrica.

\section{Métodos}

\section{PRÉ-TRATAMENTOS DOS FILMES}

Os filmes de polietileno de baixa densidade (PEBD), polietileno de alta densidade (PEAD) e policloreto de vinila (PVC) foram tratados pelo método da oxidação. Os filmes foram imersos em uma solução de $\mathrm{KMnO} 4$ $0,1 \mathrm{~mol} \mathrm{~L}^{-1} / \mathrm{HCl} 0,2 \mathrm{~mol} \mathrm{~L}^{-1}$ durante 7 horas, à $80^{\circ} \mathrm{C}$. Após esse período, os filmes foram retirados da solução e lavados com água destilada ${ }^{4,5}$.

Os filmes apresentaram a superfície recoberta por uma camada superficial escura de dióxido de manganês, gerado pela reação de decomposição do $\mathrm{KMnO} 4$, evidenciado pela seguinte equação. Para a retirada do dióxido de manganês aderido à superfície dos filmes foi necessário imersão dos mesmos em solução de $\mathrm{HCl} 0,1$
mol.L-1 por 10 minutos à temperatura ambiente6.

\section{OBTENÇÃO DOS COMPÓSITOS}

Os compósitos produzidos: $\mathrm{PEAD} / \mathrm{CuS}$, PEBD/ $\mathrm{CuS}$ e PVC/CuS foram obtidos da mesma forma. Suas amostras, já com a superfície oxidada, foram imersas em uma solução de $\mathrm{CuSO} 4.5 \mathrm{H}_{2} \mathrm{O}\left(0,2 \mathrm{~mol} \mathrm{~L}^{-1}\right) /$ tiossulfato de sódio $\mathrm{Na}_{2} \mathrm{~S}_{2} \mathrm{O}_{7} \cdot 5 \mathrm{H}_{2} \mathrm{O}(0,2 \mathrm{~mol} \mathrm{~L}-1)$ com proporção de $1: 1$ $\mathrm{V} / \mathrm{V}$, com pH da solução modificado para 2,5 utilizando ácido fosfórico $\left(\mathrm{H}_{3} \mathrm{PO}_{4}\right)$ concentrado. As amostras ficaram imersas em banho termostatizado durante 2 horas em uma temperatura de $80^{\circ} \mathrm{C}$, com agitação constante ${ }^{1}$.

\section{Resultados e Discussões}

Os resultados obtidos pelas análises dos espectros infravermelho das amostras oxidadas de PEBD e PEAD são mostradas nas Figuras 1 e 2, respectivamente.

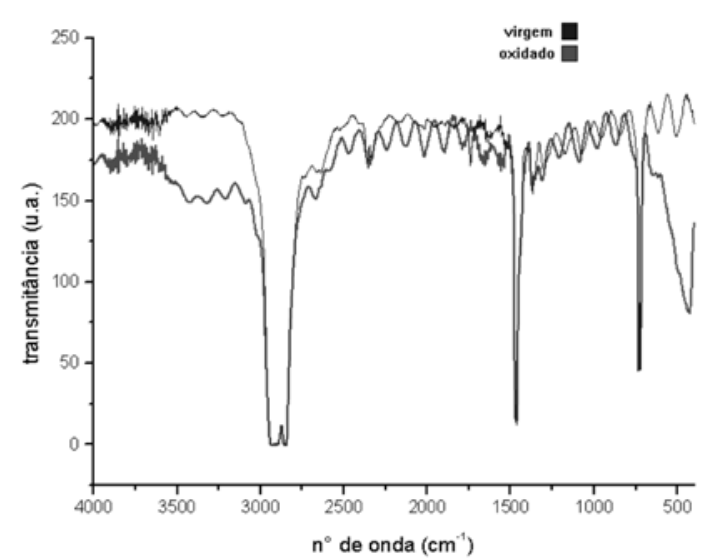

Figura 1: Espectrofotometria de infravermelho para PEBD virgem e oxidado.

Analisando o gráfico para o PEBD podemos perceber claramente bandas fortes em 2800 e $3000 \mathrm{~cm}^{-1}$, além de bandas médias nos valores de $1480 \mathrm{~cm}^{-1}$ e $740 \mathrm{~cm}^{-1}$ características do PEBD, isso vem afirmar o fato de que o processo de oxidação dos filmes não altera o interior do polímero uma vez que tanto o virgem quanto o oxidado apresentam essas mesmas bandas. Uma diferença entre a amostra virgem e a amostra oxidada está em uma nova banda encontrada para baixos valores de número de onda. Esses valores são de ligações $\mathrm{C}-\mathrm{Cl}\left(615 \mathrm{~cm}^{-1}\right)$ e C-Cl 3 (420 
a $320 \mathrm{~cm}^{-1}$ ) que ocorreram durante a oxidação devido a forte presença de $\mathrm{HCl}$ na solução oxidante. Outra análise importante é o aparecimento de duas bandas fracas nos resultados das amostras oxidadas em cerca de $1720 \mathrm{~cm}^{-1}$. Essas bandas podem ser atribuídas à presença de dois grupos sendo um deles o carbonílico $(\mathrm{C}=\mathrm{O})$ representado pela banda com número de onda de $1710 \mathrm{~cm}^{-1}$, e o outro o carboxílico (-COOH) representado no gráfico pela banda no valor de $1724 \mathrm{~cm}^{-1}$. Essas novas bandas de absorção observadas no infravermelho realçam a modificação da

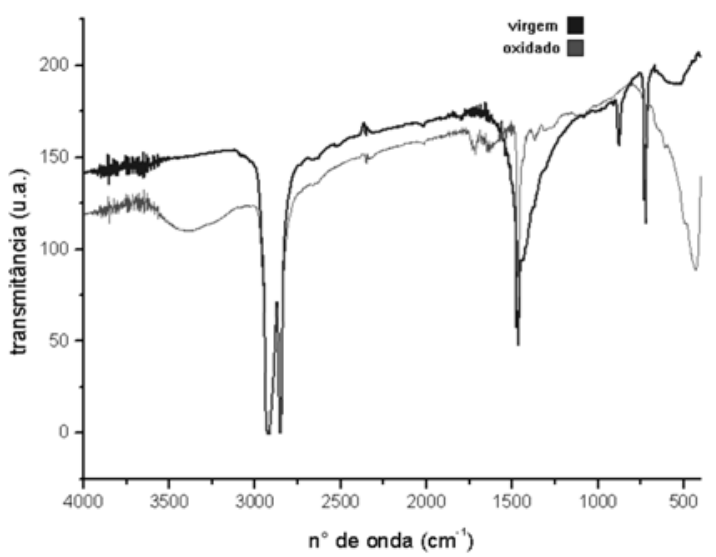

Figura 2: Espectrofotometria de infravermelho para o PEAD virgem e oxidado

superfície do PEAD pela oxidação.

Os resultados de PEAD ficaram bastante parecidos com os anteriores para PEBD, isto porque são formados do mesmo monômero, mudando apenas a forma com que as moléculas estão arranjadas na cadeira polimérica. As mesmas discussões anteriores cabem para estes resultados.

Os valores encontrados para a condutividade dos compósitos polímero/CuS estão apresentados na Tabela 1.

Para os valores encontrados nos testes dos compósitos de polímeros com o cobre podemos perceber um considerável aumento na condutividade, que pode ser atribuída à adesão de cobre na superfície polimérica, uma vez que o polímero puro seria um isolante em potencial. Com o cobre em sua superfície o material teria orbitais moleculares livres permitindo assim o fluxo de elétrons por esses orbitais, daí a condutividade encontrada. Esses
Tabela 1: Resultados de condutividade obtidos pelo método de quatro pontas para as amostras dos compósitos $\mathrm{PEAD} / \mathrm{CuS}$ e $\mathrm{PEBD} / \mathrm{CuS}$.

\begin{tabular}{lc}
\hline Compósito & Condutividade Média $(\mathrm{S} / \mathrm{cm})$ \\
\hline PEAD/SCu & 0,957 \\
\hline PEBD/SCu & 1,220 \\
\hline
\end{tabular}

valores obtidos para os compósitos de cobre ainda são baixos quando comparado com metais puros, no entanto para utilizarmos como um material semi-condutor poderia ter uma ótima eficiência. Comparado com outros materiais de mesmo custo de obtenção poderíamos ainda associar sua condutividade com as características dos polímeros, pois essas não sofreram alterações significativas sendo que o interior do polímero não sofre nenhuma alteração, apenas a superfície. Isso pelo fato de que o permanganato de potássio normalmente ataca os grupos carboxilas, transformando-os em íons carboxilatos que, então se ligariam ao sulfeto de cobre. Mas isto não ocorreu em grande quantidade nos polímeros analisados uma vez que estes não possuem muitos grupos carboxilas, esta análise pode ser reforçada pelo fato de um maior valor de condutividade encontrado nas amostras de PEBD. O que difere o PEBD do PEAD quanto aos grupos carboxilas é a quantidade presente na estrutura molecular. O PEBD possui uma cadeia polimérica ramificada e isso nos dá uma maior quantidade de extremidades ao longo de sua estrutura, logo, uma maior quantidade de carboxilas uma vez que apenas nas extremidades encontramos os grupos $\mathrm{CH}_{3}$, no meio da cadeia é encontrado apenas grupos $\mathrm{CH}_{2}$. No PEAD sua cadeia polimérica é linear e isso ocasiona uma menor quantidade de extremidades, e com isso, um menor número de grupos carboxilas. Utilizando essa análise para os compósitos PVC podemos explicar a não condutividade observada neste, sua estrutura praticamente não possui grupos capazes de sofrer oxidação.

\section{Conclusões}

Neste presente trabalho chegamos à conclusão de que a oxidação dos filmes poliméricos realmente causa uma significativa modificação estrutural na superfície deste, confirmada pelos espectros de infravermelho, que deixam a superfície dos filmes sujeitas a ligações covalentes de novos grupos sem alterar as características no interior do 
polímero.

A capacidade de oxidação superficial aumenta do PVC passando pelo PEAD e chegando ao PEBD como o polímero mais suscetível à oxidação.

Podemos também concluir que é possível impregnar os filmes poliméricos oxidados com sulfeto de cobre, porém não em grande quantidade capaz de aumentar significativamente a condutividade deste material.

\section{BIBLIOGRAFIA}

1. Kunita, M. H.; Impregnação de Superficie de Polímeros com Sulfeto de Cobre para a Obtenção de compósitos de Baixa Resistência Elétrica, Dissertação de Mestrado apresentada ao Departamento de Química da Universidade Estadual de Maringá - Maringá, PR, p.5-25, 2001.

2. Herrmann Jr. P. S. de P.; Polímeros Eletrônicos: Novos Materiais para o Século 21 e suas Potenciais Aplicações no Agronegócio, Embrapa Instrumentação Agropecuária, São Carlos e Universidade Texas, Dallas, 2004.

3. Maia, D. J.; De Paoli, M. A.; Síntese de polímeros condutores em matrizes sólidas hospedeiras, Química Nova, vol.23 n.2, São Paulo, 2000.

4. Costa, R. A.; Gonçalves, M. C.; Oliveira, G.; Rubira, A. F.; Galembeck, F.; Polyethylene Adhesion: Pretreatment with Potassium Permanganate. Journal of Applied Polymer Science, 37p. 3105-3117 (1989).

5. Yamamoto, T.; Tanaka, K.; Kubota, E.; Osakada,
K.; Deposition of Copper Sulfide on the Surface of Poly(ethylene terephthalate) and Poly(vinyl alcohol) Films in the Aquoius Solution Solution to Give Electrically Conuctive Films. Chemistry of Materials, 5 : (9), p. 1352-1357 September (1993).

6. Tanamati, A. A. C.; Compósitos de Poliolefinas com Óxidos Metálicos; Obtenção e Propriedades Peroxidásica. Dissertação de Mestrado apresentada ao Departamento de Química da Universidade Estadual de Maringá - Maringá, PR (1992).

Trabalho parcialmente desenvolvido como parte das atividades de pesquisa da Faculdade de Tecnologia SENAI Roberto Mange (FATEC SENAI RM), e apresentado no I Simpósio de Inovação Tecnológica, realizado em Anápolis, de 14 a 16 de Agosto de 2008.

\section{Fernando Afonso da Silva*1, Eliete Fernandes Martins Madeira' \& Katienne Aparecida de Jesus Linhares ${ }^{1}$}

${ }^{1}$ Faculdade de Tecnologia SENAI Roberto Mange, CP 355, CEP 75113630, Anápolis, GO, Brasil.

*E-mail: fernandoa.senai@sistemafieg.org.br 